\title{
Medical ethics education: a professor of religion investigates
}

\section{Author's abstract}

A study was carried out in a large teaching hospital to ascertain the current view of members of ten ward teams in regard to certain problems in the field of medical ethics. The investigator accompanied each team on their morning rounds and sat in on their discussions. At the end of each week he interviewed the faculty member, residents, intern, and medical students who comprised that team. Responses to these fifty open-ended interviews were grouped into categories that seemed natural to the data. These were tabulated and commented upon. The conclusions drawn were that there is an urgent need for ethical discourse in medical education, but that there are certain built-in difficulties in bringing this about in a significant way. Focus of attention upon critical incidents that come up in the normal cycle of ward rounds appeared to be the optimum approach to take.

When I first began to take an interest in medical ethics, I was considerably sobered by a remark made by a professor in the College of Medicine. 'Next thing you know, they'll be coming over here from the College of Liberal Arts and telling us how to run our business.' He was afraid that humanists (American for academics working in the humanities-Editor.) with armchair philosophies and vague generalities would not understand the urgent, on-the-spot crises he and his colleagues confronted daily at the bedside or in the emergency room. Although I had been associated with hospitals for over 30 years, mostly as a clinically oriented trainer of clergy and chaplains, I realised that as a non-MD, I lacked credibility in this field. The doctor was right to be defensive; many humanists come to the medical scene as reformers and they often feel it is denigrating to their high calling to expect their discipline to provide some practical or applied service, and for that very reason, have not been keen to come forward to assist in the workplace. Such mutual distrust has been cited by Ruddick in a booklet describing the efforts of the Philosophers in Medical Centers Project in New York City (I). My academic home base is in

\section{Key words}

Teaching of medical ethics; medical ethics and medical education. such areas as psychology of religion, pastoral theology, and clinical pastoral education. I was clearly stepping over the line.

\section{Method used in this study}

The plan of this study was to observe ten different teams for a week as they made their ward rounds. As a $\bar{z}$ participant observer I chose to try to immerse myself in the perspective, daily routine, and experiences of the attending staff faculty member, the resident (usually a $\vec{\oplus}$ third-year trainee), a couple of interns (first-year residents), and usually two third-year medical students. Weinholtz used this method in studying the overall approach to medical education (2). I was trying to get a feel for how the patient's case was being worked up, what went into the decision-making about treatment, $\frac{\mathrm{D}}{\mathrm{D}}$ and how any medical ethics issues might be approached by the team.

The daily schedule went as follows:

I) 'Morning report', which was a meeting of all residents in the office of the Head of the Department of Internal Medicine, lasting from about 8. I 5 until 9.1 5. Here residents reported new admissions, discussed patient management problems, administrative details 3 and policies, and took turns presenting special didactic topics. It gave the Head and Chief Resident a chance to know what was going on in the department as well as to teach as questions and issues arose.

2) Ward rounds lasted from one and a half to two hours during which all patients for which the team was responsible were visited. There was discussion before and after each visit.

3) A didactic session followed in which the staff ${ }_{\mathrm{C}}^{N}$ member went over the $x$-rays, explained further the diagnostic complexities and prognostic problems, oro perhaps talked more fully about a syndrome which had $\overparen{\varnothing}$ been observed in a particular patient that day. These $\stackrel{\oplus}{+}$ activities usually lasted until noon.

Although occasionally I asked a question I was primarily there in the role of observer. On a few occasions I was asked to visit a patient with special needs, $\stackrel{\mathbb{Q}}{\mathbb{Q}}$ which I did.

At the end of each week I interviewed all members of the team. By this time I had developed some rapport, 0 and the team members knew that I had seen what they 
had seen in terms of patient condition, diagnostic problems, management dilemmas, family context, likely prognosis, etc. These interviews were open-ended and unstructured, so there was much opportunity to draw upon the unique perspective of each person. Nine topics were raised for discussion (3). The purpose was to see what impact these ethical questions made upon the respondents, how they dealt with such problems, and what factors needed to be dealt with in their resolution. The final topic concerned whether, and if so how, medical ethics issues should be dealt with in medical education. Interviews generally lasted from 30 to 40 minutes.

The main benefit of this participant/observer role for me was that I was able to see the many complex factors which make each case unique. It is one thing to speak quite confidently about the futility of further treatment of an obviously 'terminal' patient one day, and quite another to see, three days later, that same person getting stronger and more coherent and finally walking about his room. One gets a feel for how the exception to the rule can actually establish policy, at least in the minds of some.

\section{Sample}

The study was limited to ten ward teams within the Department of Internal Medicine. Four categories of persons comprised the teams: attending staff (faculty); senior residents; interns (first year out of medical college), and medical students. Since this was a descriptive study, no effort was made to obtain a statistically significant sample of either faculty or students. The sample represents roughly a tenth of the faculty of $8 \mathrm{I}$ in the Department of Internal Medicine; 20 students out of a total class of 175 , and a higher percentage of interns and residents, 20 out of a total of 83 on the staff.

Most of the areas observed were patient wards through which a very large percentage of the junior class of students and residents would rotate sometime during the year, for one month at a time. The faculty also changes on most patient wards each month. Several wards served general internal medicine patients for diagnosis and treatment purposes of various types. Others 'were more specialised: pulmonary,.' haematology-oncology, gastro-intestinal, and cardiology.

An effort was made by the interviewer not to slant questions or statements; and, with only an intuitive judgment to go on, it appeared that all respondents were willing to be quite for uright and candid in their replies. Since I had no influence over their future career p:ospects it seemed I was viewed as an objective and legitimate investigator. All participants seemed interested in hearing the results of my findings.

\section{Method of collating data gathered from interviews}

The method of collating the responses made during the open-ended interviews was as follows. All responses to a given item were listed in sequence with check-marks made after statements which were repetitious of those already recorded. Later, responses which were very similar and dealt with the same concept or dynamic, were grouped under over-arching headings. Thus the categories grew from the data themselves. This is in contrast to the type of questionnaire which limits the respondent's choices to four or five pre-determined categories. While ease of statistical handling of the results is lost, one gains added nuances and a fuller expression of the thoughts and feelings of the respondents.

\section{Responses}

THE USE OF SCARCE MEDICAL RESOURCES

Nearly half of the respondents believed that intensive care units and sophisticated technology were over-used - with the caveat that such resources should be reserved for patients who were 'salvageable'. An almost equal number responded in terms of distributive justice: resources, including money, were not limitless, and social implications of large investments for few persons needed to be taken into account. Reference was also made to the suspicion that when exotic resources were made available they tended to be used whether they were needed or not.

\section{DOCUMENTS AND GUIDELINES}

Two-thirds of the respondents did not make any use of the 'Patient's Bill of Rights'. (This document was approved by the American Hospital Association in 1972 and delineates many policy statements concerning medical ethics.) Either these respondents had not read it, did not remember it, or had neither used it nor discussed it on ward rounds. The same may be said for the Department of Internal Medicine's guidelines for cardiopulmonary resuscitation. It seems one cannot count on printed material, protocols, etc being made use of.

\section{VOLUNTARY INFORMED CONSENT}

The question of voluntary informed consent (one of the principles highlighted in the 'Patient's Bill of Rights') was taken very seriously by the majority, who favoured autonomy of the patient: the ratio of those who favoured autonomy to those who still favoured paternalism was two to one. Autonomy emphasises the responsibility of the patient to make decisions and hence the necessity for adequate information. Paternalism emphasises the vulnerability of the patient and his/her weakened condition necessitating a more active role on the part of the physician. Interestingly, there was no correlation between these replies and the rank or status of the respondents.

\section{PROLONGATION OF LIFE}

As might be expected, there were those who stressed the many variables influencing decisions in individual 
cases, which some cited in detail as examples of the kind of problems confronted. They said that medicine was not an exact science as many laity assumed, and that it was sometimes not possible to foresee the course of a terminal illness, whereas in other instances the trajectory was fairly obvious. Other variables included the family, who were often involved in granting consent in lieu of an unconscious relative patient, or in urging that heroic measures be employed when the physician was less than enthusiastic about such a course of action.

Those who came down firmly on one side or the other fell into two distinct categories; in much the same ratio as cited above concerning consent, with the large majority favouring the 'conservative' approach:

Conservative - restraint in use of extra-ordinary means, leaning toward the 'natural death' or 'death with dignity' orientation

Radical - intensive use of life-prolongation measures until the very end, leaning toward 'the doctor can't play God' attitude

Interestingly, the Hippocratic phrase 'do no harm' (non nocere) was used on both sides: it might be doing harm to prolong the dying process, thus adding artificially to someone's suffering; and it might be doing harm to cut off any, even a slim, possibility of further human experience. Some made both pro and con statements.

Mention was made of a distinction along religious lines indicating that Roman Catholics were more likely to believe in intensive use of life-prolongation measures. This would have been an interesting question to explore in the light of the fact that a long time ago, in 1957 , a papal statement was made indicating that heroic measures were not morally mandatory if there were no therapeutic benefit or hope of recovery. The religious factor was not explored in this study. However, it does highlight the problem of practising medicine in a pluralistic society where there can be great diversity within the medical team as well as among the patients.

\section{TRUTH TELLING}

Here again, following the trend toward more patient autonomy, a large majority was in favour of telling the patient fully all the pertinent facts about diagnosis and prognosis in language the patient could understand. Only one in ten had any reservations about this, or about truth telling in general.

\section{CARDIOPULMONARY RESUSCITATION}

Nearly half of those questioned felt that any 'Do not resuscitate' order should be discussed with the patient in advance (and with the family if the patient was not competent). A significant minority stated that cardiopulmonary resuscitation (CPR) should not be used with patients who were terminally ill and were of the opinion that CPR was performed too frequently.

SHOULD MEDICAL ETHICS BE TAUGHT?

In this instance there was a complex overlapping of ideas and suggestions. For example, a large number, $\overrightarrow{0}$ who believed there was a need for discussion of medical $\frac{\partial}{\partial}$ ethics issues, also believed it was futile or impossible to $\frac{\bar{m}}{b}$ deal with a subject so subjective and metaphysical in a $\overparen{\otimes}$ structured way. Another group believed it was needed but could only be gained by experience and matura- ${ }^{\circ}$ tion. A third group, while acknowledging its useful- $\vec{?}$ ness, stated that by this stage of the student's (resi- $\overrightarrow{\vec{\omega}}$ dent's) development the individual either had or had $\stackrel{\omega}{\circ}$ not developed whatever ethical-moral capabilities he/she was going to acquire.

\section{Observations on the team rounds process}

The teams consisted of hard-working eager people, $\vec{z}$ each team gradually becoming a cohesive unit by virtue of having to focus again and again upon the very intri- $\stackrel{\rho}{\mathcal{S}}$ cate problems of patients. I have little doubt that for a $\vec{\varphi}$ very, very high percentage of the time members of all $\mathbb{\omega}^{\infty}$ of the teams were personally interested in and concerned about each individual patient.

The second impression was the vast amount of statistical data the members seemed to have at their finger tips. Numerous tests yielded numerical readings $\frac{\circ}{\circ}$ whether describing blood pressure, fluid intake and $\mathrm{O}$ urine out-put, weight, potassium, calcium or blood $\overrightarrow{\hat{O}}$ gases. Often there were 20-25 different numbers writ- 3 ten on a $3^{\prime \prime} \times 5^{\prime \prime}$ card which the student or resident held in his/her hand. There also seemed to be the mental orientation necessary to be able to assimilate and retain these numbers in great detail.

A third observation concerns the complexity of the student's or resident's day. Before and after rounds.physicians-in-training checked back with the patient to $\mathrm{O}$ obtain a written consent for some procedure; to explain 2 the results of a lab test; to get to know them better so as 윽 to assess better the family context, or to obtain any $>$ other missing information which could be funnelled into the chart. One could sense that there were many N private conferences and discussions among two or three of the members. There seemed to be no limit to the number of things that needed to be taken into account.

The pressure of time hung over everything. If, for

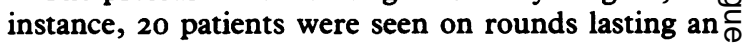
hour and twenty minutes, that averaged only four minutes per patient. That included the pre-visit brief- $\square$ ing, the visit and any physical examination, and the

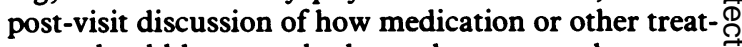
ment should be started, changed, or stopped.

If it is true that medical students have already been screened for a capacity to focus on minute data and for the kind of concrete thinking needed for the basico sciences, it also seems obvious that even their clinical 
experience hones this capacity to a razor sharpness. The cognitive style I observed was indeed concrete, specific, and sequential. 'Certain factors led to this condition; now if we do the following things we can hope for these results.' Here I saw another contribution to the sharp division between the medical sciences and the humanities. Humanists tend to be conceptual and abstract in their thinking; they deal in principles, generalisations, basic presuppositions, theories, etc. Medical science is a tangible subject whereas the work of the humanists is conceptual or structural. Obviously there are individual differences within both academic disciplines on this continuum from concrete to abstract, from sequential to conceptual thinking; but from my observation, while the physician is making rounds, the strong impetus is to lean toward concrete and sequential thinking. If I were a patient I would not like my physician to be vague and general about my vital signs: I would be grateful for precision and specificity. But when it comes to ethical decision-making, such concrete thinking alone does not suffice.

In short, as a result of my investigation, I gained some empathy for what the members of the medical team were up against as I began to understand the difficulties of relating - under pressure - to patients, the many ambiguities facing them, and the probabilistic nature of the practice of medicine. The investigation helped me, as a representative of the humanities, to have a more realistic appreciation of the work of my colleagues in the field of medicine, especially as seen in the process of the education of a physician.

\section{Interpretations of the findings of the inquiry including reflections}

One can draw several conclusions from the responses to the topic about the teaching of medical ethics. First, it is an example of what C P Snow called the 'Two Cultures', whereby the field of science and the realm of the humanities are seen as discrete disciplines between which communication is perceived by some as unnecessary, by others, as difficult $(4,5)$. Some medical students, who would not think of jumping to a conclusion concerning a diagnosis, assume it is quite all right to leap to an ethical decision because 'either you believe it is right or you don't believe it is right'. Thus some students of the 'hard sciences', such as anatomy, biochemistry, and physiology, do not believe that hard thinking is either necessary or possible in such fields as philosophy, ethics, theology or other humanities. This prevents the cross-fertilisation which could enrich both spheres of human experience.

Secondly, there is confusion and misunderstanding about what is involved in medical ethics. It is not simply a matter of arriving at 'right' answers. Ethical discourse is concerned with how one goes about analysing value-laden problems. It seeks out underlying presuppositions and requires the person to be explicit about his/her principles and rationale for getting from point $A$ to point $B$. How are the various competing and conflicting claims to 'rights' and 'obligations' to be sorted out and fitted into an equation which yields a meaningful and coherent answer? It is not enough even to do the right thing if it is done for the wrong reason. Just as pathology blows the whistle on irresponsible surgery, so ethics monitors loose and irresponsible thinking in decision-making.

Thirdly, there is an assumption that medical ethics is needed only rarely, in a few dramatic life-and-death issues such as the Karen Quinlan case or a Jehovah's Witness blood transfusion court case. Besides, the thinking goes, it seems to have little practical value for medical training since it will not be covered in the examinations one needs to pass in order to qualify. Given the heavy work-load students face this view is surely understandable.

In university hospitals where medical ethics prospers, the value of the subject is whole-heartedly accepted by the attending physicians, the faculty, and leading residents. The humanist in these circumstances is not handicapped by lack of grasp of the technical, bio-chemical, and medical knowledge because there is an openness to such input by physicians and biological researchers in a team atmosphere.

What of the practical benefits to the team, especially the students and residents? Part of the excess baggage of those attending the sick is misplaced responsibility. It is bad enough to have a heavy load to bear but not to understand why it is all right to cease treatment when it is no longer therapeutic, not to realise it is not always your fault when a patient dies, not to be able to share appropriate autonomy with a patient concerning decisions - all these impediments make being a physician more burdensome than necessary.

\section{References}

(I) Ruddick W ed. Philosophers in medical centers. New York: The Society for Philosophy and Public Affairs, I 980.

(2) Weinholtz D. A study of instructional leadership during medical rounds. Chapel Hill, North Carolina: University of North Carolina, PhD dissertation, I981.

(3) A more detailed description of the study will be mailed by the author to anyone who requests it: address University of Iowa Hospitals and Clinics, Iowa City, Iowa 52242, USA.

(4) Pellegrino E D. Humanism and the physician. Knoxville, Tennessee: The University of Tennessee Press, 1979.

(5) Schaefer K E, et al, ed. Toward a Man-centered medical science. Mt Kisco, New York: Futura Publishing Company, 1977. 